\section{THE GERMAN NAVAL OBSERVATORY}

$\mathrm{I} \mathrm{T}$ will be remembered by our readers that in the spring of the present year a review of the sixth yearly Report of the German Naval Observatory at Hamburg was given (NATURE, vol. xxxiii. p. 4II), in which the objects and the general system of working in the several departments, as well as some special papers on subjects connected with the $\mathrm{Cb}$ bervatory, were noticed.

In this, the seventh yearly Report, there is the same evidence of the progress of useful work in all departments described in the first of the four papers which it contains, but not requiring special remark. In Paper No. 2, however, there is a detailed account of the building in which this work is carried on, and a general description of the instruments employed, which can hardly fail to be of interest even to those who may have personally visited the Observatory.

The traveller approaching the docks of Hamburg by the Elbe, will see a square sandstone building in the Renaissance style situated on an eminence which rises abruptly 100 feet above the river, between Altona and Hamburg. This is the Naval Observatory, in an excellent position for observations, and commanding an extensive view of surrounding objects for many miles, close to the shipping for the welfare of which it was chiefly established, and as it were inviting the commanders to come and partake of the advantages held out to them. The main building - which in plan forms a hollow square, and consists of a basement, ground floor, and two stories above, with ample internal galleries and staircases for communication with the various rooms-was commenced in 1879 and completed in October $\mathrm{I} 88 \mathrm{I}$, a Naval Exhibition in the lower rooms having been opened in the previous month by the Emperor of Germany in person.

Over the principal entrance, which faces towards the south-west, are three busts of well-known scientific worthies, that of Dove being in the middle, with Maury and Rümker right and left. The square inside the building is roofed with glass, giving protection to the galleries and the Combe apparatus which occupies the floor, whilst it proves but a small obstruction to the light.

A view from the north-west side of the building will be found on Plate I, and on Plate 2 a plan showing the general disposition of the adjoining structures.

Preceded by some historical references to the site now occupied by the Observatory--where fortifications formerly existed-in pp. 5-12 will be found a description of the uses to which the various rooms are devoted, with references to the twenty-nine excellent plates, showing their size, and the mounting of the various instruments in them, both in elevation and plan. At each angle of the building there is a low square tower. On the western of these the anemometers and wind-vane are mounted, with electrical communications to the registering apparatus. In the south tower is the apparatus for proving sextants, for which the known angles between well-defined distant objects are used, it being a rare occurrence for the latter to be obscured by fogs. A transit instrument occupies the eastern tower, and an alt-azimuth instrument the northern.

From pp. 12-26 detailed accounts are given of the principal normal and self-registering instruments, the laboratory, the compass observatory, and the museum with its contents. Amongst the special apparatus a registering rain-gauge is described at p. 27 , with an illustration ; this, with the sliding-weight barograph described on p. 29, was designed by Dr. A. Sprung.

The magnetic pavilion in the garden is chiefly devoted to experimental determinations of the induction-coefficients for various kinds of iron, and instruction to students in magnetism.

r "Aus dem Archiv der Deutschen Seewarte." VII. Jahrgang, r884. Herausgegeben von der Direcktion der Seewarte. (Hamburg, 1886.)
Some remarks on the uses of the Combe apparatus, founded on information of a later date than that of the present Report, may possibly be of interest. A doubt has already been expressed (NATURE, vol. xxxiii. p. 4II) as to the value of the effects produced on chronometers by machinery for simulating the rolling and pitching motion of a ship at sea. This doubt has been confirmed by experience, and some additions have been made to the apparatus by which the effects of shaking such as might be caused by the racing of the engines on board ship or the blow of a heavy sea are introduced. These effects of shaking are clearly shown in the rates of the chronometers tried.

As the Combe apparatus can be rapidly revolved by means of a gas engine, its uses have been extended to the trial of anemometers and the measurement of windpressure, the arrangements for which may be seen on Plate 18 , and a description of the same on pp. I2-I5. It is reported that the results obtained are satisfactory with the exception of minor effects on the anemometers caused by draughts passing through the arched openings to the adjoining corricor, but this is in a fair way to be accurately accounted for.

In Paper No. 3, the course of instruction used by students at the Observatory on the mathematical treatment of the deviation of the compass, with examples, is shown in detail. A certain knowledge of mathematics and mechanics is required of the students preliminary to this instruction, but they have the assistance of Dr. Neumayer's deviation model (NATURE, vol. xxxiii. p. 587) for experimental illustration.

The formulæ used are, with one exception, those of the Admiralty Manual for Deviations of the Compass, published in London in 1869.

The exception will be found on pp. 29 and 30 , where it may be seen that a new term is introduced into each of the equations representing the fore-and-aft and transverse magnetic forces of an iron ship. The object is to give a mathematical expression for the temporary changes which are produced in an iron ship's magnetism when her course lies in a given direction for a few days, or even hours, under certain conditions-the change only becoming apparent on alteration of the course. The amount of change experienced depends upon the quality of the ship's iron, the position of the compass, the length of time she is kept on the given course, the degree of shaking she is subjected to during that time, and is proportional to the earth's magnetic force at her mean geographical position. The question is more fully discussed in the Archiv der Deutschen Seewarte for I879, No. 4, where some values of the changes denoted by the constants $V$ and $V^{\prime}$ for certain ships are tabulated, but these values are dependent on so many contingencies, that nothing but carefully-conducted observations systematically made for each ship can give exact results. It may be remarked, however, that from results of the kind just described properly analysed, much useful information might be deduced and furnished to iron vessels proceeding on a voyage, as to the probable changes in their magnetism under various conditions.

The general rule at present is to depend entirely on observations of the deviations of the compass and their registration for future guidance when observations cannot be obtained. There is much to be said in favour of this rule, but there is also much to be hoped for from the more scientific treatment. It may be added that as similar results are often obtained in vessels of like types of construction, the analysis of observations from many vessels is much to be desired for the guidance of commanders of vessels starting on their first voyage, possibly, in weather when objects on land or in the sky are invisible.

In the fourth and concluding paper an account is given of the observations made by Dr. Richard Neuhauss during a voyage from Germany to Australia by the Suez Canal 
route, returning by New Zealand, Samoa, the Sandwich Islands, San Francisco, and New York. The observations relate principally to barometrical heights, temperature of air and sea, moisture of the atmosphere, and twilight phenomena, including zodiacal light, whilst passing through the Red Sea and tropical portions of the Indian and Pacific Oceans.

Although in previous yearly Reports Dr. Neumayer has published much information respecting the internal working, aims, and results of the Observatory he so ably directs, it is only from the perusal of this seventh Report that a full idea of the pains which Germany has taken on behalf of her sea-going population, in building and equipping at considerable expense the noble Naval Observatory at Hamburg, can be obtained. It should also be remembered that there are several minor affiliated institutions in Germany of like intent.

\section{THE INSTITUTION OF MECHANICAL ENGINEERS}

$\mathrm{A}^{\mathrm{T}}$ the recent meeting of the Institution of Mechanical A Engineers, held in Leeds under the presidency of Mr. Jeremiah Head, a paper was read "On Triple-Expansion Marine Engines," by the late Mr. Robert Wyllie of Hartlepool. During the last few years the high-pressure triple-expansion engine has proved the successful rival of the double-expansion compound, and the object of the paper was to bring forward the results of recent experience with this new type of engine, and to consider briefly the various points which have a direct bearing on its efficiency, as well as the most suitable design for marine purposes. The general conditions of efficiency were stated to depend on the approximate equality in the range of temperature in each cylinder, in the initial stress on each crank, and in the indicated horse-power of each engine. As complementary to these are steam-jacketed cylinders and other matters which are first treated of. As regards steam-jackets, when in triple-expansion engines attention is paid to the equal division of the total range of temperature amongst the cylinders in which the successive stages of expansion take place, the benefits arising from the use of steamjackets are naturally not so great as in single-cylinder engines with a high rate of expansion ; but however carefully the triple engine may be designed, the jacketing of at least the intermediate and low-pressure cylinders is essential to maximum efficiency. The ratio of the cylinder capacities depends on the pressure of the steam and type of engine, the high-pressure cylinder being larger in proportion where large range of power and economy of fuel is not so important, as in war-ships as compared with cargo steamers. To obtain even approximate equality in powers, temperatures, and stresses requires the greatest care in designing the steam-passages throughout the engine, so that the velocities of the steam at the various points and the degrees of cut-off by the valves may be carefully proportioned. Too much care cannot be taken in the design of the steam-ports and exhaust-passages of the low-pressure cylinder. The ports should be as small as possible to reduce the clearance to a minimum, and the speed of the entering steam should not be so high as to cause excessive frictional resistance, nor that of the exhaust so high as to augment the back-pressure, and consequently the greatest efficiency is obtained when the revolutions and indicated horse-power are not required to vary to any great extent. Contracted or indirect exhaust-passages in the high-pressure and intermediate cylinders have the effect of causing a larger difference between the back-pressure on one piston and the initial pressure on the next, thus diminishing the efficiency of the steam. The cut-off necessary for the highest efficiency is governed to a great extent by the speed of the entering steam and the nature of the passages. In the interme- diate and low-pressure cylinders, too high a velocity of the entering steam will produce excessive frictional resistance, causing a drop in the expansion-curve, as well as unduly high receiver-pressure, thus disturbing the equality of temperatures and of initial stresses. Some diversity of opinion has existed as to the order of sequence for the three cranks. The author considered the best sequence to be the high-pressure leading, lowpressure following, and intermediate last. As regards the number of cranks, the best design is to have two cylinders on each crank for a two-crank engine on the triple-expansion system, as it is then possible to get an approximately equal initial stress on each crank, the arrangement necessitating one of the three stages of expansion taking place in two cylinders instead of in one. A marine engine should be so designed that any working part can be easily examined or removed, the arrangement of cylinders on three cranks fulfilling the required conditions more nearly than any other design. The requirements of a good valve-gear are, that it shall give at both ends of the cylinder an equal distribution of steam at all grades of expansion, with a minimum of working parts and no undue strains. The four principal methods are : by the single eccentric, by the double eccentric, by taking the motion from the connecting-rod, and by a compound motion derived from both the piston-rod and the connecting-rod; all have their advantages and defects, and vary considerably in complexity and multiplicity of parts. A comparison of practical results with compoundand triple-expansion engines is in favour of the latter, as regards dead-weight carried, speed, indicated horse-power, and coal-consumption, the latter being so low as I $4 \mathrm{I}$ lbs. per h.p. per hour, proving this class of engine to be most efficient. The paper concluded with a reference to artificial draught for boilers, in the special arrangement described the air being heated both inside and outside the uptake, balanced fire doors being applied, which on being opened shut off automatically the hot air supplied by the fan both above and below the fire-bars.

An important discussion followed the reading of the paper. Mr. Wm. Parker, of Lloyd's, looked upon the triple-expansion engine as the engine of the future. Profs. Kennedy and Smith drew attention to the high initial pressures employed in the triple engine, 150 lbs. per square inch as compared with 75 lbs. per square inch in the compound engines being the cause of their higher efficiency; and other speakers having drawn attention to special features in the designs, the further discussion of the paper was put off to the spring meeting of the Institute.

Afterwards the President, by request, declared the Leeds Engineering School of the Yorkshire College open, and spoke in hopeful terms of the useful work it had doubtless before it.

\section{NOTES}

WE regret to have to announce the death last week of Dr. Guthrie, Professor of Physics at the Normal School of Science.

WE understand that the Jardin des Plantes has acquired for its botanical collections the herbarium of Lamarck. We do not know under what circumstances this had travelled so far from France. But until recently it was the property of Dr. Roeper, Professor of Botany in the University of Rostock. He incorporated it with his own herbarium, and the whole was purchased at his death by the University for $2 \mathrm{I}, 000$ marks (1050l.). Lamarck's plants have however been separated, and as we understand purchased by the French Government.

THE front and sides of the new building for the galleries of natural history in the Jardin des Plantes are now nearly complete. But it will be two years or nearly so before the interior and the fittings can be finished. The collections will then be moved into the new portion, and the present galleries rebuilt to form the back of the square. The hollow interior will be covered 